Manolakis Al., Bordei P., Dina C., Iliescu D.M.

\title{
Peculiar case of branching of the trachea together with both, main and lobar, bronchi into a fetal lung
}

Discipline of anatomy, Department I - preclinical disciplines, Faculty of medicine, University "Ovidius" Constanţa

\begin{abstract}
Using as study method the injection of plastic followed by corrosion, we described, on an 8 months fetal lung, a particular branching pattern of the right bronchial tree were the superior lobar bronchus arise on the right side of the trachea, at $4.1 \mathrm{~cm}$ cranial to tracheal bifurcation. Other features of tracheo-bronchial branching encountered in this case: the level and tracheal bifurcation site and origin and the trajectory of the main bronchi, the middle lobar bronchi of the right lung and apical bronchus of the inferior lobar bronchi. To these peculiarities of the tracheo-bronchial tree are described also the peculiarities of the pulmonary arteries branches, which accompanies bronchial ramifications.
\end{abstract}

Keywords: trachea, bronchi, branching

\section{Iliescu D.M.}

Department of Anatomy, Faculty of medicine, University "Ovidius" Constanța, Romania

Aleea Universitatii, Nr. 1, Campus B

Constanţa, Romania

dan@anatomie.ro

\section{Introduction}

The two main bronchi arise through the bifurcation of the trachea to the left of the midline $[1,2,3,4,5,6]$, while $[7,8]$ state that the bifurcation is easy to the right of the midline. Tracheal bifurcation is located at the level of the T5 vertebra [3,7,9], at T5T6 intervertebral disc (Rouviere), at the T4 vertebra $[1,2,4]$. According to [10], the tracheal bifurcation anteriorly corresponds to the sternal angle or second intercostal space. By [3], to the left of the tracheal bifurcation is the pulmonary artery trunk bifurcation. At the level of its bifurcation, trachea forms, between the two main bronchi, an angle of $70^{\circ}[3,5,6], 50-70^{\circ}$ [9] or $75-85^{0}[1,2]$. According to [8], the bifurcation of the trachea forms, with the vertical plane, an angle that does not exceed $20-30^{\circ}$. The right main bronchus is tilted, being nearly vertical, with vertical in adults making an angle of $30^{\circ}$, while in child this angle is larger [1], and with the median plane an angle of $20^{\circ}$ [9]. It has a length of $2-2.5 \mathrm{~cm}$ [2] or a length of 2.5 $\mathrm{cm}[4,5,6,7]$. The right upper lobar bronchus emerges 
from the main bronchus under a right angle, $2-3 \mathrm{~cm}$ from the tracheal bifurcation [8], having a superior anterior and lateral direction $[8,9]$, showing a variable length of $1 \mathrm{~cm}[4,5,6], 1.5 \mathrm{~cm}$ [9] or $2 \mathrm{~cm}$ [1]. The middle lobar bronchus originates caudally from the superior at a distance of $2 \mathrm{~cm}[4,5,6]$ or even $5 \mathrm{~cm}$ [1]. The lower right lobar bronchus, orientated lateral, posterior and inferior has a length not exceeding 1 $\mathrm{cm}$ [8]. The apical bronchus of the inferior lobe originates near the middle lobar bronchus [8]. The left main bronchus is slightly inclined, having almost horizontal path [7], forming with the median plane an angle of $45^{\circ}$ [9] or $55^{\circ}[1,2]$, this angle being slightly smaller in child [1]. It has a length of $5 \mathrm{~cm}[1,2,4,7,8]$. The upper left lobar bronchus was 1 [9] up to $5 \mathrm{~cm}$ from the bifurcation of the trachea $[3,8]$, the lingular bronchus having a length of $1 \mathrm{~cm}$ [8]. The lower left lobar bronchus shows the origin of the apical bronchus at $1 \mathrm{~cm}$ caudally to the origin of the upper left lobar bronchus [4].

\section{Materials and methods}

Our case has been described within a 8 months fetal lung, in which we first observed and described the external conformation, after which they were injected with plastic into the tracheo-bronchial tree (yellow), and pulmonary arteries (blue), using Technovit 7143. After the injection the corrosion was carried out with $\mathrm{NaOH}$.

\section{Results}

The superior right lobar bronchus detaches from the lateral side of the trachea, at $4.1 \mathrm{~cm}$ cranial to tracheal bifurcation and $2.1 \mathrm{~cm}$ cranial to the right pulmonary artery trunk. At origin, its lower surface form with the right lateral side of the trachea an angle of $82^{\circ}$. At $1.1 \mathrm{~cm}$ from the origin it splits in an anterior superior branch and an inferior posterior branch, which is more voluminous, with almost vertical direction and parallel to the front right side of the trachea. It is designated for the posterior segment of the upper pulmonary lobe. The corresponding arterial branch originates from the right pulmonary artery at $1.1 \mathrm{~cm}$ from its origin. The right pulmonary artery arises on the left side of the trachea, in his way to pulmonary hilum passing above the tracheal bifurcation at $1.2 \mathrm{~cm}$ cranially, crossing anteriorly the right main bronchus at its origin and on the lateral side of the main bronchus gives rise to the middle lobar artery, $0.8 \mathrm{~cm}$ cranially to the middle lobar bronchus.

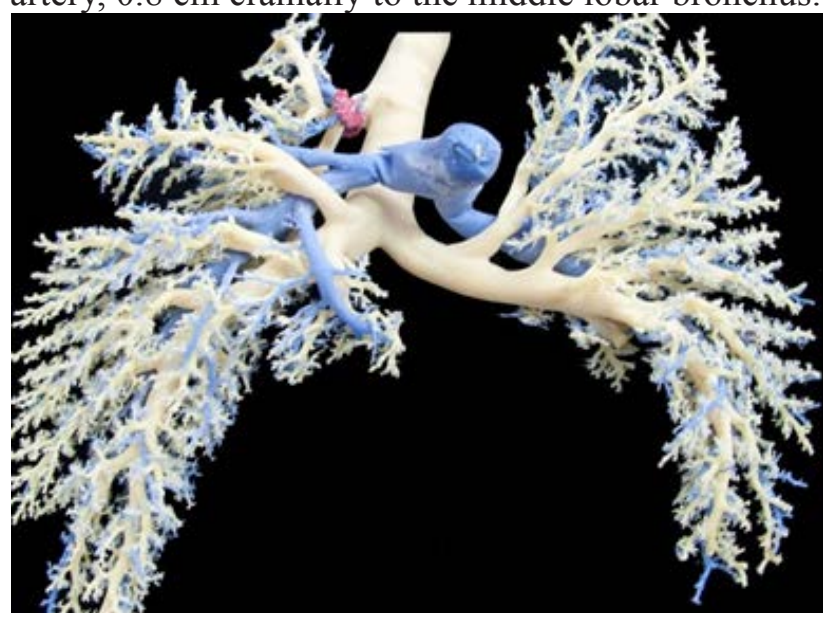

Figure 1 - Anterior view

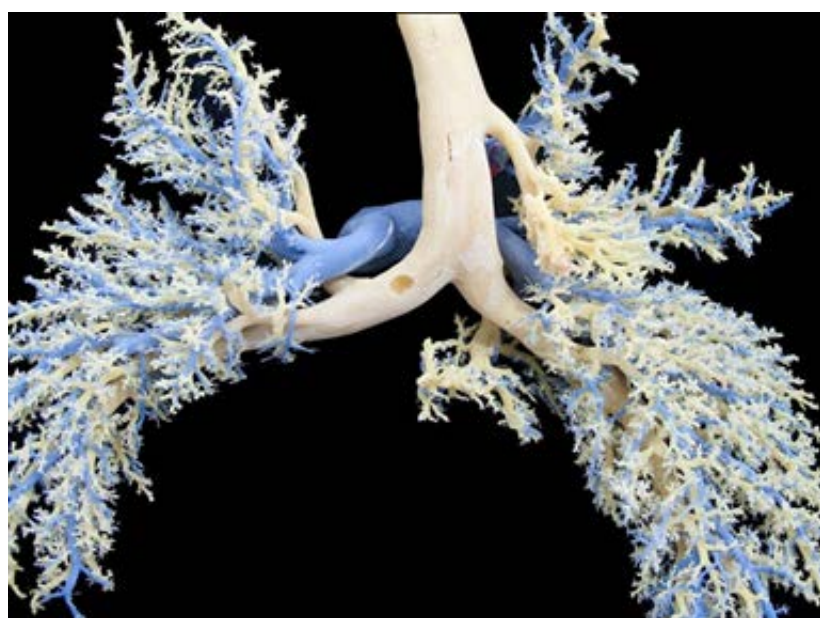

Figure 2 - Posterior view 
The superior lobar arterial branch emerges from the right pulmonary artery in front of the trachea, having a supero-lateral path, ending by bifurcation in front of the upper lobar bronchus.

The trachea bifurcates at an angle of $90^{\circ}$, the right main bronchus being more voluminous than the left one. The right main bronchus has a more inclined direction than the left one, its upper side forming with the right lateral flank of the trachea an angle of 1780 and with the midline forming an angle of 450 . The middle lobar bronchus originates from the main bronchus at $1.3 \mathrm{~cm}$ from the tracheal origin of the right main bronchus. On a distance of $0.9 \mathrm{~cm}$ has a horizontal trajectory, after which it becomes slightly oblique upward and laterally passing anterior to the artery, to bifurcate in front of it. The right pulmonary artery is located supero lateral to the lobar bronchus at the level of middle lobar artery.

The left main bronchus has a direction less inclined than the right one, closer to the horizontal, its upper side forming with the left lateral flank of the trachea an angle of 860 . The superior lobar bronchus originates on the upper face of the main bronchi at $1.6 \mathrm{~cm}$ from its tracheal origin, with a supero-lateral oblique direction and upwards, making with the left side of the bronchial origin an angle of 680 . It divides at $1.2 \mathrm{~cm}$ from its origin, serving the upper left lobe. At $1 \mathrm{~cm}$ caudal to the origin of the upper lobar bronchus, on the upper surface of the left bronchus, originates the apical bronchus of the inferior lobe which bifurcates at $0.5 \mathrm{~cm}$ from origin, making with the left side of the main bronchus an angle of 450 . The left pulmonary artery originates on the left side of the trachea at $1 \mathrm{~cm}$ and $1.4 \mathrm{~cm}$ cranially to the tracheal bifurcation. Up to the upper lobar bronchus is located superior and lateral to the left bronchus, then move superior and posterior to the superior and apical lobar bronchus of the inferior lobe, under the apical bronchus disposing posterior to the bronchus. The apical arterial branch originates from the pulmonary artery at $1 \mathrm{~cm}$ caudally to the superior lobar arterial branch.

\section{Discussion}

The superior right lobar bronchus detaching from the trachea and not from the main bronchus can be embryologically explained. According to [12], during the separation of proenteron, the pulmonary bud give rise to the trachea and two lateral prominences, the bronchial buds. At the beginning of the fifth week, the two buds grow in size and form the main bronchi, right and left. According to [13], the laryngo-tracheal diverticulum emerge on the ventral wall of the anterior intestine and begins to suffer a series of divisions from 4th week of embryonic development, forming two branches (right and left lung buds) that will form the main one, so it would be about pulmonary bud early cleavage (laryngo-tracheal diverticulum), which will give rise the superior right lobar bronchus, while the remaining pulmonary bud follows their normal development. The superior right lobar bronchus early origin results in a reduction in size of the right main bronchus [9].

Comparing other details of our case with literature data, we specify the followings:

- the apical bronchus of the inferior right lobe originates halfway between the middle lobar bronchus and the inferior right basal bronchus;

- the apical bronchus of the inferior left lobe originates halfway between the superior lobar bronchus and the inferior right basal bronchus;

- the right pulmonary artery is located supero lateral to the right bronchus and away from it (0.2-0.3 $\mathrm{cm}$ ), up to the level of the middle lobar bronchus, at which it comes in contact with it and after that passes posterior to the inferior bronchus;

- the left pulmonary artery is located supero lateral to the left bronchus and away from it (0.3$0.5 \mathrm{~cm}$ ) up to the level of the apical bronchus of the inferior lobe, at which it comes in contact with bronchus and after that passes posterior to it;

- the middle lobar bronchus originates as an early bifurcation of the main right bronchus, which so has an very short trunk; 


\section{Conclusion}

It's a rare case that we did not encountered within literature, the fetus not showing other abnormalities or variants at the level of systems and organs. The existence of this bronchial branch results in origin variations of the middle lobar bronchus (which has its origin from the right main bronchus near the tracheal bifurcation) and apical segmental bronchus of the right inferior lobe (which has its origin in relation to basal bronchi). We note also the particular disposal of the arterial branches in relation to the bronchial branches that accompany it.

\section{References}

1. Testut, L. (1949). Conduit trachéo-bronchic. In: Traité d'Anatomie Humaine. Livre III. Appareil de la respiration ét de la phonation. (pp. 788-804). Paris: Ed. Gaston Doin

2. Testut, L. (1921). Traité d'Anatomie Humaine. Livre VIII. L'apareil respiratoire. (pp. 890-900). Paris: Ed. Gaston Doin

3. Rouvière, H. \& Delmas, A. (1997). Anatomie Humaine. Déscriptive topographique et fonctionnelle. Tome 2. Tronc. 14-édition. (pp. 279-308). Paris: Ed. Masson

4. Standring, S. (2005). Trahee and bronchi. In: Gray's Anatomy. The Anatomical Basis of Clinical Practice. (pp. 1075-1078). Ed. Elsevier Churchill Livingstone

5. Kamina, P. (2007). Vaisseaux pulmonaires. Trachée et bronches. In: Anatomie clinique. Tome 3. Thorax, Abdomen. (pp. 61-72). Paris: Ed. Maloine

6. Kamina, P. (1997). Trachée et bronches. In: Anatomie. Introducțion à la clinique. Vol.11, Dos et thorax. (pp. 139-147, 158-163). Paris: Ed. Maloine

7. Beauthier, J.P. \& Lefevre, Ph. (1993). Traité d'anatomie, de la théorie à la pratique palpatoire. Tome 3. Tête et tronc. Propédeurique viscérale. (pp. 236-241). Bruxelles: Ed. De Boeck Univ.

8. Bouchet, A. \& Cuilleret, J. (1991). Anatomie topographique, descriptive et fonctionnelle. Tome 2. Le cou. Le thorax. (pp. 699-706, 11131140). Paris: Ed. SIMEP

9. Chevrel, J.P. (1994). La trachée. Les poumons. In: J.P.Chevrel, Anatomie clinique. Le Tronc. (pp. 213-230). Paris: Ed. Springer-Verlag

10. Moore, K. \& Dalley, A. (1993). Anatomie clinique. Aspects fondamentaux et application clinique. (pp. 100-108). Bruxelles: Ed. De Boeck Univ.

11. Langman, J. \& Sadler, T.W. (1996). Embryologie médicale-6 edition. (pp. 252-258). Paris: Ed. Pradel

12. Cochard L. (2003). Atlas d'embryologie humaine de Netter. (pp. 120-126). Paris: Ed. Masson

13. ********* Terminologia Anatomica. International Anatomical Terminology. (1988). Federative Committee on Anatomical Terminology. (pp. 59-61). Stuttgart: Thieme Verlag 